\title{
En memoria de
}

Pedro Angulo Pinto

(1927-2014)

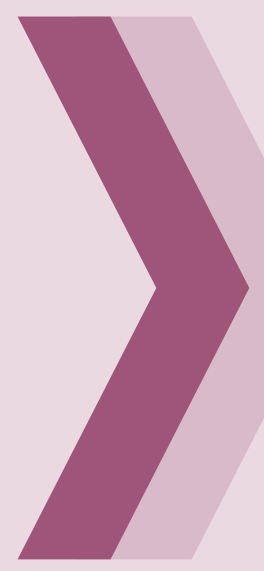

In memory of

Pedro Angulo-Pinto

(1927-2014)

\section{Bertilo Malpartida-Tello}

1. Cirujano cardiovascular. Doctor en Medicina. Exdocente de la UNMSM, Cayetano Heredia y Federico Villarreal. Presidente del Directorio de Clínicas Limatambo.

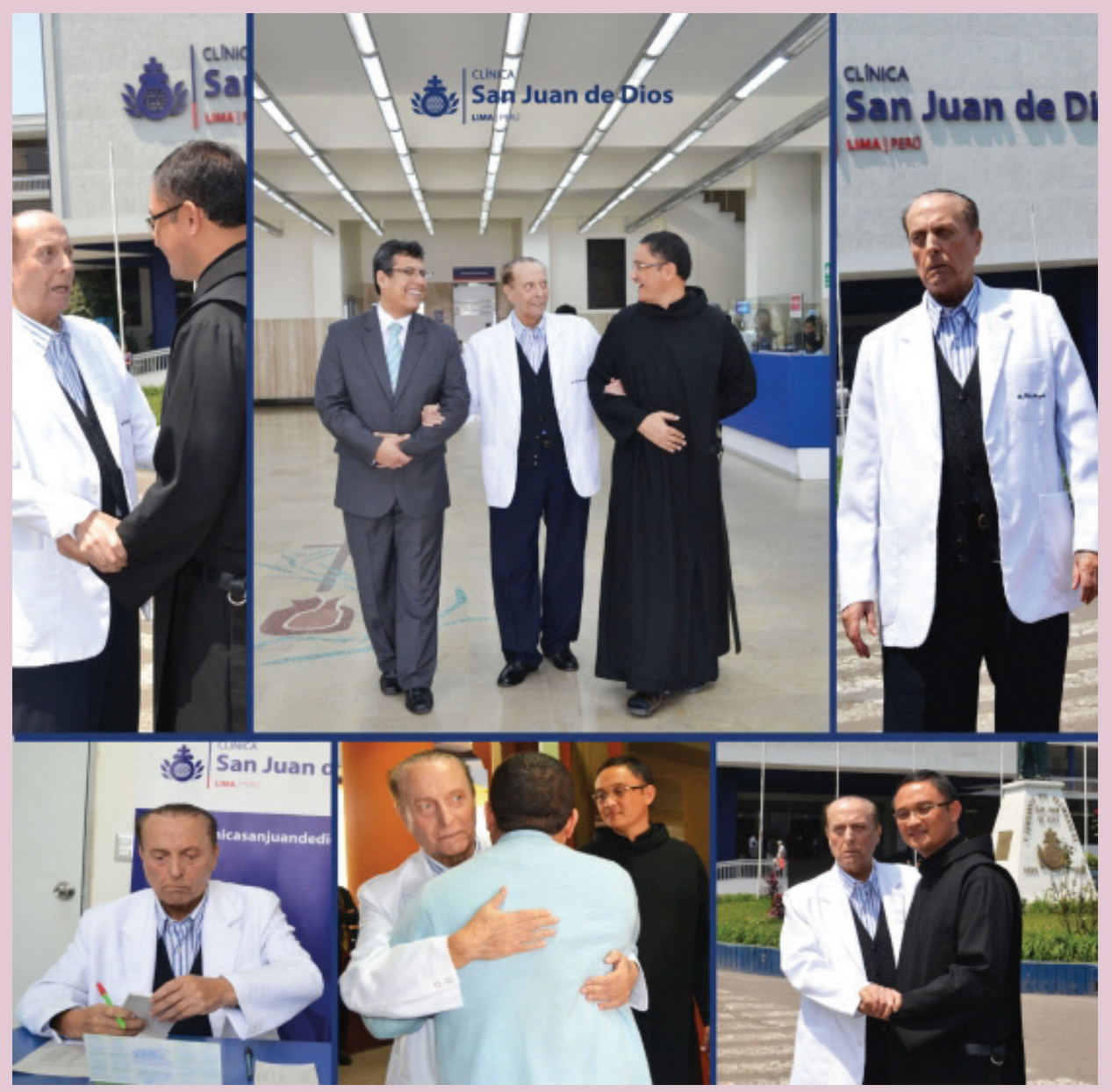


Pedro Angulo Pinto nació en Lima el 13 de mayo de 1927 . Formó parte de una familia de cuatro hermanos, con quienes tuvo una infancia feliz; la madre de profesión obstetra, dotada de cualidades especiales, fue quien sacó adelante su hogar. Después de terminar sus estudios secundarios aconsejado por su hermano estudiante de Medicina, ingresó a la Facultad de Medicina de San Fernando, de la UNMSM, donde al terminar sus estudios fue el primero en juramentar de un grupo de más de 300 alumnos. Se casó y formó una familia con cinco hijos; se divorció y después de unos años encontró una compañera ideal, quien supo comprenderlo y querer a sus hijos y nietos como suyos. Su mayor éxito en la vida es el haber dado profesión a todos sus hijos; uno de ellos vive en New York, dos en Madrid y dos en Lima.

Pedro Angulo Pinto, Pedro a secas como se le llamaba de cariño, ha trabajado más de 50 años en el Hospital San Juan de Dios de manera gratuita como cirujano ortopédico, sucesivamente como médico asistente, jefe de servicio, jefe de consultorios desde 1954 y finalmente, director. Trabajó diez años (1956-1968) en el Hospital Obrero de Huacho como médico asistente y luego como jefe de Ortopedia, Traumatología y Rehabilitación. Se trasladaba una vez por semana al Hogar Clínica San Juan de Dios para contribuir con su trabajo. Laboró durante los años 1966-1970 en el Hospital Obrero de Lima (Almenara) como médico asistente del departamento de Rehabilitación. Luego se trasladó al Hospital Hipólito Unanue, donde llegó a ser jefe del departamento de Cirugía. Fue elegido presidente del Cuerpo Médico en dos oportunidades y director médico de ese nosocomio (1984-1985) y posteriormente director médico del Hogar Clínica San Juan de Dios (1997-2003).

Ha sido presidente de la Academia Peruana de Cirugía, en donde fue miembro honorario, así como de otras sociedades médicas importantes. También ocupó los cargos de presidente del Patronato Peruano de Rehabilitación y profesor de Rehabilitación en Salud y Deporte en Salud.

Como docente ha sido profesor en la UNMSM, formando médicos especializados, principalmente en Medicina Física y Rehabilitación y Ortopedia. Fue el iniciador de la Escuela de Tecnología Médica, Medicina Física y Rehabilitación. Fue autor de numerosos libros, memorias, estudios, artículos y otras publicaciones. También, director fundador de la Revista de la Sociedad Peruana de Ortopedia y Traumatología, director de la Revista de la Academia Peruana de Cirugía y otras importantes revistas más. Ha recibido distinciones y honores en su ejercicio profesional.

Galardonado con los premios "Fortunato Quesada”, "Aníbal Corvetto", Fundación "Hipólito Unanue", medalla de profesor emérito de la Universidad Federico Villarreal y medalla "Madre Teresa de Calcuta". Recibió, asimismo el reconocimiento al "Ilustre maestro", por las clínicas "Limatambo". $\mathrm{Ha}$ tenido reconocimiento especial por sus méritos alcanzados y excelente labor profesional como docente, investigador y compañero, por su compromiso con la calidad de vida de sus pacientes y valiosa contribución al progreso de la investigación en la traumatología.

Pedro Angulo Pinto ha sido un hombre lleno de todas las virtudes, amante de la ciencia médica, gran colega en cualquier circunstancia, ha apoyado a las nuevas generaciones de ortopedistas y traumatólogos y ha tenido un comportamiento ejemplar con sus pacientes, engriendo a los más pobres y necesitados; por eso hasta sus últimos días participó activamente ad honórem en el Hogar Clínica San Juan de Dios. Abandonó este mundo el 8 de noviembre de 2014, dejando un inmenso vacío entre sus familiares, amigos, discípulos, compañeros y colegas, pero su noble ejemplo y sabias enseñanzas perdurarán por siempre.

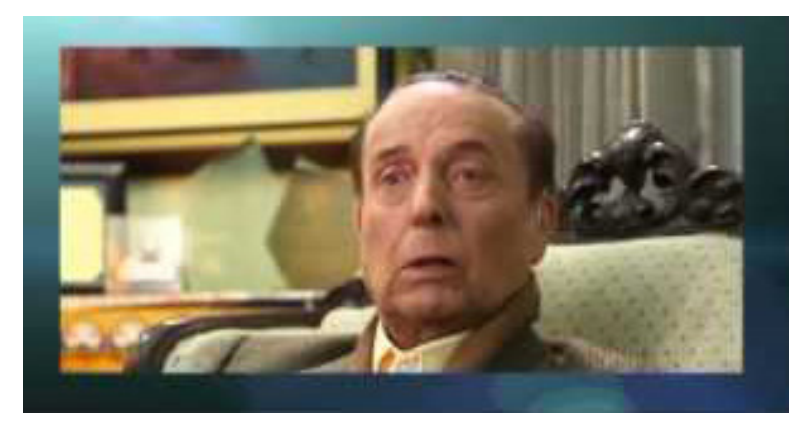

\section{Correspondencia}

Dr. Bertilo Malpartida-Tello bmalpartidat@hotmail.com 